\title{
Proceeding
}

Supplementary Issue: Spring Conferences of Sports Science. Costa Blanca Sports Science Week, 26-28 April 2018. Calpe. Alicante, Spain

\section{Motivation and physical fitness in old people participating in a hydro-gymnastics}

\author{
CARLOS MANUEL NUNES FARINHA ${ }^{1}$, J.P. FERREIRA² ${ }^{2}$ J. SERRANO \\ ${ }^{1}$ Faculty of Sport Science and Physical Education, University of Coimbra, Portugal \\ 2Physical Activity and Sport Research Centre (CIDAF), Sport Sciences and Physical Education Faculty, \\ University of Coimbra, Portugal \\ ${ }^{3}$ Sport, Health \& Exercise Research Unit (SHERU), Polytechnic Institute of Castelo Branco, Portugal
}

\begin{abstract}
Introduction: The purpose of the present investigation was to evaluate the motivations and the impact of the hydro-gymnastics in the physical fitness of old people involved in a 16 weeks exercise program. Methods: Participants were 83 old people doing a community hydro-gymnastics exercise program. Motivations were assessed using the Sport Activity Motivation Questionnaire and physical fitness was evaluated using the Functional Fitness Test battery, in two separate moments with a 16 weeks interval. The assumption of normality was checked using the Kolmogorov-Smirnov test. Wilcoxon test was used to compare the group in different time moments. Results: Regarding motivations to hydro-gymnastics the items that scored higher were: "need to exercise", "be with friends", "make new friends" and "fun". In terms of physical fitness variation, improvements in average were found in practically all fitness test between the $1^{\text {st }}$ and $2^{\text {nd }}$ evaluation, with significant statistical differences in 3 of the 5 tests applied. Conclusions: Old people's major motives to participate in hydro-gymnastics are related to the motivational dimensions of physical fitness, general affiliation and pleasure. Additionally, hydro-gymnastics exercise programs have a positive impact to improve physical fitness in old people and play a determinant role on health promotion and successful aging. Key words: AGEING, OLD PEOPLE, EXERCISE, MOTIVATION, PHYSICAL FITNESS.
\end{abstract}

\section{Cite this article as:}

Farinha, C.M., Ferreira, J.P., \& Serrano, J. (2018). Motivation and physical fitness in old people participating in a hydro-gymnastics. Journal of Human Sport and Exercise, 13(2proc), S363-S369. doi:https://doi.org/10.14198/ihse.2018.13.Proc2.20

Corresponding author. Faculty of Sport Science and Physical Education, University of Coimbra, Portugal.

E-mail: cmnfarinha@gmail.com

Supplementary Issue: Spring Conferences of Sports Science. Costa Blanca Sports Science Week, 26-28 April 2018. Calpe. Alicante, Spain.

JOURNAL OF HUMAN SPORT \& EXERCISE ISSN 1988-5202

(c) Faculty of Education. University of Alicante

doi: 10.14198/jhse.2018.13.Proc2.20 


\section{INTRODUCTION}

In an increasingly aging country, where average life expectancy has been rising, it is essential to realization research and investigations aimed at the aging process in order to make it more stable and with the highest possible quality. On the other hand, it is also important to make this process free of chronic pathologies, thereby reducing the costs associated with the treatments they add.

As aging is considered an inevitable and progressive process, where there is a decrease in all physical capacities and physiological functions (Filho et al., 2010, p.98), increases the importance of attempt to counteract this, making the line of aging more linear and stable, and not so progressive and constant. Thus it is important to know the motivations of this type of population to provide motivational and accessible activities that, simultaneously, which provides improvement of the quality of life (Taveira, 2010).

One of the causes of the aging process is the decrease in levels of physical fitness: reduction of muscle strength, flexibility, agility, etc. which simultaneously, go contribute to a reduction in mobility and autonomy thus affecting the performance of daily activities and increasing the risk of accidents (like falls). This process may still diminish the motivation for social life contributing to critical isolation of the elderly. According to Rikli and Jones (1999, p. 165), physical fitness is considered as the capacity that someone have to develop the normal activities of daily life in an independent and safe way without in the development of these activities, it is verified an extreme level of fatigue.

The practice of hydro-gymnastics, due to the characteristic properties of the environment in which it develops, provides some benefits for the elderly population offering them lower health risks. Beyond of this provide socialization, because it is a modality performed in a group, also provides benefits in terms of muscle strength, flexibility, coordination, balance and cardiovascular system (Gaines 2000, Bonachela, 2001 e Alves et al., 2004).

Taking into account the importance of providing healthier aging and autonomous, and considering that the practice of hydro-gymnastics contributes to an increase in the quality of life of the elderly population, the present study aims to understand the motivation that induce the elderly to practice physical activity and verify the impact that the practice of hydro-gymnastics provides in the physical fitness level of this population.

\section{METHODOLOGY}

\section{Sample}

Based on the study objective, was defined as target population, old people with over 55 years of age, of both genres and practitioners of hydro-gymnastics. Participation in the study was performed on a voluntary being that, the total sample consisted of 83 old people, practitioners of hydro-gymnastics classes.

\section{Instruments}

To evaluate the motivations that induces the elderly to practice physical activity was using the Sport Activity Motivation Questionnaire (Serpa \& Frias, 1991). The questionnaire is constituted by 30 items being the same divided into 8 categories: status, emotions, pleasure, competition, physical fitness, skill development, general affiliation, and specific affiliation. For this study, only 20 items were analyzed, divided into 7 categories: status, emotions, pleasure, competition, physical fitness, skill development and general affiliation. For each of the items, the participant assigns a score of 1 to 5 according to their degree of importance, being that 1 is considered as being nothing important and 5 as totally important. 
How many physical fitness levels, were applied 5 test of the battery Functional Fitness Test battery (Rikli \& Jones, 1999): get up and sit on the chair, arm curl, sit and reach, timed up and go and reach behind the back.

\section{Data collection}

The Sport Activity Motivation Questionnaire was applied only at the beginning of the study and was completed by the participants in a large and calm room with the presence of the researcher.

The physical fitness tests were applied at 2 moments, separated by 16 weeks. In both evaluation moments all the tests were applied by the investigator before the start of the hydro-gymnastics classes, following the test protocol of Rickli and Jones (1999), in a suitable room for the effect.

\section{Statistical Procedure}

Relatively the Sport Activity Motivation Questionnaire, a qualitative descriptive analysis was performed. Relatively the results of the physical fitness assessment tests it was made a descriptive statistical analysis which reported values the mean, minimum, maximum and standard deviation. Subsequently, the Kolmogorov-Smirnov test was applied to verify the normality of the data. Then Wilcoxon test (nonparametric test for two paired samples) was used to compare the group in the different time moments.

For treatment and parameterization of the data collected was used SPSS software version 21.0, where all the statistical treatment was performed with a level of significance of $5 \%(0.05)$.

\section{RESULTS}

As for the results related to the motivations, obtained through the application of the questionnaire we can say that (Table 1), the items that have assumed a higher degree of importance, being classified as important, very important and totally important, were: exercise (99\%), fun (98\%), being with friends (98\%), make new friendships (98\%), take action (98\%), being in good physical condition (96\%), release stress (94\%), have something to do $(94 \%)$, discharge energies (93\%), maintaining physical shape $(92 \%)$, improve technical capacity (92\%), pleasure in the use of installations and sports equipment (87\%), belong to a group (82\%), travel $(79 \%)$ and pretext to leave home $(77 \%)$.

Table 1. Results (Sport Activity Motivation Questionnaire)

\begin{tabular}{|c|c|c|c|c|c|c|}
\hline $\begin{array}{l}\text { Motivational } \\
\text { dimension }\end{array}$ & Items & N.I. & P.I. & I. & M.I. & T.I. \\
\hline \multirow{5}{*}{ Statute } & Travel & $6 \%$ & $15 \%$ & $44 \%$ & $18 \%$ & $17 \%$ \\
\hline & Pretext to leave home & $10 \%$ & $13 \%$ & $30 \%$ & $26 \%$ & $21 \%$ \\
\hline & Have the feeling of being important & $33 \%$ & $23 \%$ & $32 \%$ & $7 \%$ & $5 \%$ \\
\hline & Be known & $25 \%$ & $30 \%$ & $32 \%$ & $5 \%$ & $8 \%$ \\
\hline & Be recognized and have prestige & $27 \%$ & $18 \%$ & $34 \%$ & $14 \%$ & $7 \%$ \\
\hline \multirow{3}{*}{ Emotions } & Discharge energies & $5 \%$ & $2 \%$ & $42 \%$ & $30 \%$ & $21 \%$ \\
\hline & Have strong emotions & $16 \%$ & $21 \%$ & $38 \%$ & $15 \%$ & $10 \%$ \\
\hline & Release stress & $2 \%$ & $4 \%$ & $32 \%$ & $38 \%$ & $24 \%$ \\
\hline
\end{tabular}




\begin{tabular}{llcrrrr}
\hline \multirow{3}{*}{ Pleasure } & Have something to do & $2 \%$ & $4 \%$ & $40 \%$ & $31 \%$ & $23 \%$ \\
& Fun & $1 \%$ & $1 \%$ & $37 \%$ & $37 \%$ & $24 \%$ \\
& Pleasure in the use of installations and & $1 \%$ & $12 \%$ & $35 \%$ & $31 \%$ & $21 \%$ \\
& sports equipment & $12 \%$ & $18 \%$ & $40 \%$ & $19 \%$ & $11 \%$ \\
\hline Competition & Overcoming challenges & $2 \%$ & $6 \%$ & $29 \%$ & $37 \%$ & $26 \%$ \\
\hline \multirow{5}{*}{ Physical fitness } & Keep in shape & $1 \%$ & $0 \%$ & $30 \%$ & $36 \%$ & $33 \%$ \\
& Exercise & $0 \%$ & $2 \%$ & $35 \%$ & $40 \%$ & $23 \%$ \\
& take action & $2 \%$ & $2 \%$ & $36 \%$ & $33 \%$ & $27 \%$ \\
\hline Development of & Be in good physical condition & $4 \%$ & $4 \%$ & $50 \%$ & $30 \%$ & $12 \%$ \\
competences & Improve technical capacity & $1 \%$ & $1 \%$ & $31 \%$ & $46 \%$ & $21 \%$ \\
\hline \multirow{3}{*}{ General affiliation } & Be with friends & $1 \%$ & $1 \%$ & $41 \%$ & $30 \%$ & $27 \%$ \\
& Make new friends & $8 \%$ & $10 \%$ & $50 \%$ & $21 \%$ & $11 \%$ \\
\hline
\end{tabular}

On the other hand, the items that assumed a lower degree of importance, being classified as nothing important, not important and important, were: Have the feeling of being important (88\%), Be known (87\%), Be recognized and have prestige (79\%) and, have strong emotions (75\%).

In the motivational dimension of competition, the item overcome challenges assumed a degree of relative importance, since the percentages of answers are divided between nothing important and totally important.

In sum, we can say that the motivations that take the elderly included in the present study to practice physical activity, are concentrated in three motivational dimensions: pleasure, physical form and general affiliation.

Relatively the results concerning physical fitness levels obtained through the application of five tests of the Functional Fitness Test Battery (Rickli and Jones, 1999), we started with descriptive statistical analysis (Table 2) for the totality sample. As we can see, in all cases, it was improvements the mean of the results of all tests applied between the first and second evaluation moments was verified. In the tests get up and sit on the chair and arm curl, which aim to assess the muscular strength of the lower and upper limbs, mean in the first evaluation was 13.40 and 18.24 repetitions (respectively) and in the second evaluation it was 14.43 and 18.94 repetitions (respectively), which means that during the same period of time the participants were able to perform more repetitions in both exercises. In the tests sit and reach and reach behind the back which aim to assess the flexibility, the means in the first evaluation were $-5.47 \mathrm{~cm}$ and $-17.07 \mathrm{~cm}$ (respectively) and in the second evaluation of $-3.46 \mathrm{~cm}$ and $15.61 \mathrm{~cm}$. Although the value of the average has decreased, it was a positive aspect because it reveals that the participants managed to reduce the distance of reach between two determined points. Finally, in the test timed up and go, which aims to assess agility and dynamic balance, the mean in the first evaluation was 6.40 seconds and in the second evaluation was 6.31 seconds. Being a timed test means that the participants reduced the time spent to travel a determined route. 
Table 2. Descriptive statistics ( $\mathrm{N}$, minimum, maximum, mean and standard deviation)

\begin{tabular}{lccccc}
\hline \multicolumn{7}{c}{ Descriptive statistics } \\
& N & Minimum & Maximum & Mean & Std. Deviation \\
\hline Get up and sit on the chair (1st moment) & 83 & 0 & 25 & 13,40 & 4,983 \\
Get up and sit on the chair (2nd moment) & 83 & 0 & 27 & 14,43 & 4,857 \\
Arm curl (1st moment) & 83 & 5 & 30 & 18,24 & 5,174 \\
Arm curl (2nd moment) & 83 & 8 & 38 & 18,92 & 5,906 \\
Sit and reach (1st moment) & 83 & -36 & 17 & $-5,47$ & 10,922 \\
Sit and reach (2nd moment) & 83 & -28 & 13 & $-3,46$ & 10,369 \\
Timed up and go (1st moment) & 83 & 3 & 26 & 6,40 & 2,811 \\
Timed up and go (2nd moment) & 83 & 4 & 20 & 6,31 & 2,208 \\
Reach behind the back (1st moment) & 83 & -59 & 9 & $-17,07$ & 12,836 \\
Reach behind the back (2nd moment) & 83 & -55 & 12 & $-15,61$ & 12,966 \\
\hline
\end{tabular}

Regarding the statistical analysis, the Kolmogorov Smirnov test was used to test the normality of the data. Since there was no normal distribution of data, was applied the teste Wilconxon (nonparametric test for two paired samples).

Table 3. Wilcoxon statistical test (sig. Value)

\section{Statistical Test - Wilcoxon}

\begin{tabular}{|c|c|c|c|c|}
\hline $\begin{array}{l}\text { Get up and sit on the } \\
\text { chair (2nd moment) }\end{array}$ & $\begin{array}{l}\text { Arm curl (2nd } \\
\text { moment) }\end{array}$ & $\begin{array}{l}\text { Sit and reach } \\
\text { (2nd moment) }\end{array}$ & $\begin{array}{l}\text { Timed up and go } \\
\text { (2nd moment) }\end{array}$ & $\begin{array}{l}\text { Reach behind the } \\
\text { back ( } 2 \text { nd moment) }\end{array}$ \\
\hline $\begin{array}{l}\text { Get up and sit on the } \\
\text { chair (1st moment) }\end{array}$ & $\begin{array}{l}\text { Arm curl (1st } \\
\text { moment) }\end{array}$ & $\begin{array}{l}\text { Sit and reach } \\
\text { (1st moment) }\end{array}$ & $\begin{array}{l}\text { Timed up and go } \\
\text { (1st moment) }\end{array}$ & $\begin{array}{l}\text { Reach behind the } \\
\text { back ( } 1 \text { st moment) }\end{array}$ \\
\hline 0,011 & 0,149 & 0,001 & 0,948 & 0,001 \\
\hline
\end{tabular}

In Table 3, we can verify that statistically significant improvements were found in 3 tests of the 5 applied: get up and sit on the chair (sig. $=0,011)$, sit and reach $($ sig. $=0,001)$ and reach behind the back $($ sig. $=0,001)$.

\section{DISCUSSION}

The literature indicates that hydro-gymnastics is a modality that besides the numerous benefits that it provides for the health of the elderly, also provides the socialization between them. The results presented, demonstrate that socialization is a central aspect for the elderly of the sample, so that the items being with friends, making new friendships and fun have assumed a high degree of importance. The item on exercise was also considered to be very important, perhaps for the perception that the participants feel the innumerable benefits that the practice of physical activity (in the aquatic environment) provides them.

The results obtained are in according with the study conducted by Vidal (2013) in Porto Alegre, where the objective was to verify the main motivational factors regarding the practice of hydro-gymnastics by women over 60 years of age. The results showed that the component health, physical rehabilitation, disease prevention and quality of life was the component that assumed a higher degree of importance, being the health issues the most motivating the practice of hydro-gymnastics for the population studied. 
In sum, with regard to the data presented on physical fitness, we can verify that the practice of hydrogymnastics had a positive impact on the elderly in the sample, regarding muscular strength, flexibility, agility and dynamic balance, being visible improvements in the means of results in all the tests applied between the two moments of evaluation, and also were found statistically significant improvements in three tests applied. Just like a study of 38 elderly people by Santos and Morouço (2015), where the objective was to analyze the effects of the application of a hydro-gymnastics program on the elderlys in terms of anthropometric characteristics and physical capacities, the main results also demonstrated that the hydrogymnastics practice significant improved the strength, flexibility and mobility for the study population.

As the results demonstrated the practice of hydro-gymnastics contributes to an improvement in the quality of life of the elderly to the sample. hydro-gymnastics can be considered a very attractive modality for the elderly, being a modality performed in a group, besides providing several benefits in physical fitness, it is also very important in socialization. However, when administering a hydro-gymnastics program, it is necessary to take into account some important aspects that may be detrimental to the health of participants, such as: exercise execution too fast, movements out of water (in particular the passage from the aquatic environment to the no aquatic environment) and, muscle imbalance.

Thus, this type of studies becomes pertinent, since the average life expectancy has been increasing, it is fundamental that beyond of longevity also there is a quality of life, can be being able to investigation may contribute to the elderly population being to survive more years with total autonomy and dependence to perform their daily activities, avoiding high costs of hospitalization and treatment associated with pathologies that come with the aging process that can be delayed with a more active lifestyle.

As a suggestion for future investigations, it is suggested that there be continuity in studies which methods can contribute to a less progressive aging, performing studies that verify the impact of different types of physical exercise programs on variables related to pathologies that are frequent in this type of population.

\section{CONCLUSIONS}

After analyzing and discussing the results, we can conclude that the motivational dimensions that assumed a higher degree of importance in our study were: pleasure, general affiliation and physical fitness. Regarding physical fitness, we can conclude that the practice of hydro-gymnastics had a positive impact on the elderly of the sample, assuming an important role in the development of a more stable and successful aging.

\section{REFERENCES}

Alves, R., Mota, J., Costa, M., \& Alves, J. (2004). Aptidão física relacionada à saúde de idosos: inflência da hidroginástica.

Bonachela, V. (1994). Manuel básico de Hidroginástica. Rio de Janeiro: Sprint.

Filho, M., Zanella, A., Aidar, F., Silva, A., Salgueiro, R., \& Matos, D. (2010). Atividade física e envelhecimento humano: a busca pelo envelhecimento saudável. RBCEH, Passo Fundo - Vol.7 (1), pp. 97-106.

Gaines, M. (2000). Actividades acuáticas ejercicios de tonificación cardiovasculares y de rehabilitación. Barcelona: Paidotribo.

Rikli, R., \& Jones, J. (1999). Functional fitness normative score for community-residing older adults, ages 60-94. Journal of Aging and Physical Activity - Vol.7 (2), pp. 162-181. 
Santos, I., \& Morouço, P. (2015). Benefícios da hidroginástica na aptidão física de idosos. Revista de Ciencias del Desporto - Vol.11 (2), pp. 157-158.

Taveira, D. (2010). Alterações nas capacidades motoras básicas, em idosos institucionalizados submetidos à prática de atividade física. Dissertação apresentada com vista à obtenção do grau de Mestre em Atividade Física na especialidade de Gerontomotricidade. Escola Superior de Educação do Instituto Politécnico de Castelo Branco.

Vidal, S. (2001). Objetivos de realização e clima motivacional nas aulas de educação física. Um estudo com alunos do $8^{\circ}$ ao $12^{\circ}$ ano de escolaridade das escolas da cidade de penafiel. Dissertação apresentada com vista à obtenção do grau de Mestre em Ciências do Desporto na área de especialização de Desporto para Crianças e Jovens. Faculdade de Ciências do Desporto e de Educação Física da Universidade do Porto. 